\title{
Apuntes cosmográficos en la primera circunnavegación de la Tierra. Fernando de Magallanes y Juan Sebastián Elcano (1519-1522)
}

Mario Ruiz Morales, Madrid, Centro Nacional de Información Geográfica, 2020, 215 pp. ISBN: 978-84-416-5640-6. DOI: https://www.doi.org/10.7419/162.02.2020

\section{Antonio F. Rodríguez Pascual Centro Nacional de Información Geográfica, España}

La primera vuelta al mundo, iniciada por el portugués Fernando de Magallanes en 1519 y culminada por el español Juan Sebastián Elcano, en 1522, constituye uno de los grandes hitos en los viajes de exploración y una aventura en la frontera de lo tecnológicamente posible en aquellos años.

Por primera vez se comprobó de manera práctica, fehaciente y ya indiscutible la redondez de la Tierra; por cierto, parece mentira que cinco siglos después siga habiendo terraplanistas. Y si bien el viaje no tuvo un impacto directo en las rutas comerciales por lo arriesgado y peligroso del periplo, supuso la primera globalización, abrió las mentes pensantes de la época, por primera vez se planteó la pertinencia de una Historia Universal, un solo mundo conectado y una economía global, y en consecuencia, nacieron multitud de iniciativas de rutas comerciales mundiales, canales de distribución y el inicio de una red de intercambios intercontinentales. Por añadidura, la circunnavegación dio lugar a avances esenciales en el progreso de la cartografía, la geografía, las técnicas de posicionamiento y otras disciplinas, como luego se verá.

De la dificultad tecnológica y marinera de la empresa, financiada por la corona española, dan idea algunos datos objetivos: fue un viaje de más de 1000 días, el más largo o uno de los más largos hasta por al momento; partieron de Sanlúcar de Barrameda el 20 de septiembre de 1519 cinco naves con 239 tripulantes y llegó al mismo puerto el 6 de septiembre de 1522 tan solo un barco con 18 hombres, y más tarde, otros 17 supervivientes que se habían quedado por el camino; el mismo Magallanes cayó en la batalla de Mactán (Islas Filipinas), en una refriega con los indígenas; el llamado Estrecho de Magallanes es un canal que comunica los océanos Atlántico y Pacífico de $565 \mathrm{~km}$ de longitud, plagado de dificultades y aparentes 
caminos alternativos sin salida, que supuso 38 días de navegación, y las grandes potencias marinas no completaron una circunnavegación hasta mucho más tarde: por Inglaterra Francis Drake 58 años después, por Italia Francesco Carletti y por Países Bajos Olivier van Noorl, ambos 79 años más tarde, y por Francia Louis Antoine de Bougainville, transcurridos 246 años. Se trata por lo tanto de una hazaña conseguida en el límite de lo posible y empujando la frontera de la tecnología, comparable en ese y otros aspectos a la llegada del ser humano a la Luna y por ello, una expedición científica única, preñada de avances e innovaciones.

Ese es el centro temático de esta obra, reseñar el impulso de la llamada entonces Cosmografía durante el viaje, y como consecuencia de la expedición. Sin embargo, el libro está aderezado de tantos detalles e información de contexto, que constituye una obra muy completa sobre la primera circunnavegación, considerando un amplio abanico de aspectos a cual más interesante.

El libro se divide en cinco capítulos y dos anexos, todos escritos con rigor histórico, resultado de un exhaustivo y prolijo trabajo previo de documentación, al mismo tiempo que con un estilo ameno, riguroso y además, clásico, a tono con el contenido a transmitir. Los aspectos cartográficos están expuestos con claridad y sencillez, gracias a la larga experiencia como conferenciante y docente universitario del autor:

- En el primer capítulo, se narran todas las vicisitudes de la preparación de la expedición y las numerosas dificultades que tuvo que sortear el tenaz Fernando de Magallanes, cuya propuesta había sido rechazada por el monarca portugués y fue finalmente aceptada por el Emperador Carlos V, la historia se repetía, tras numerosos avatares. Finalmente, consiguió pertrechar las cinco naves, con una tripulación formada por portugueses, vascos y marineros de otros países, que incluía al español Juan de Cartagena como cosmógrafo y al veneciano Antonio Pigafetta como cronista y geógrafo de la expedición.

- En el capítulo 2, se ofrece un resumen del estado, conocimiento, métodos e instrumental de la cosmografía y navegación de la época al inicio del viaje. Entonces se obtenía la latitud mediante observación a las estrellas y el gran problema era determinar la longitud, al no haber cronómetros fiables para comparar la hora local de origen con la hora solar o sidérea en cada punto de la singladura. Hasta la aparición del cronómetro de Harrison en 1764, se navegaba a estima, utilizando rumbos y velocidades de navegación.

- El capítulo 3 está dedicado a relatar las peripecias de sus tres principales protagonistas, Fernando de Magallanes, Juan Sebastián Elcano y Antonio Pigafetta, durante la famosa expedición.

- El capítulo 4 es el más notable y original de la obra, puesto que se detallan en él las observaciones astronómicas y cartográficas realizadas durante el viaje, desde 
posiciones y latitudes completamente novedosas que ofrecían visiones de la esfera celeste nunca contempladas hasta entonces, y el impacto que tuvieron en la evolución de la cosmografía y la cartografía. También se descubrieron nuevos territorios e islas, se tomó conciencia de que existía un gran océano entre América y Asia, y se realizaron numerosas observaciones botánicas, zoológicas y etnográficas.

- El capítulo 5 describe el impacto cultural y político de la primera circunnavegación, prestando especial atención a los homenajes y monumentos con los que se conmemoró la hazaña, lo que ayuda a imaginar cabalmente la impresión que produjo en la sociedad de la época.

El libro se completa con dos anexos, que contienen respectivamente, un facsímil del diario de a bordo de Antonio Pigafetta y una curiosidad: una oda a Juan Sebastián Elcano escita en 1905 por Melchor de Palau y Catalá, poeta, abogado, geólogo e ingeniero de caminos, miembro de la Real Academia Española y de la Academia de Bellas Artes de San Fernando.

En suma, una obra amena y muy instructiva, de esas que se ajustan a la antigua expresión de "instruir deleitando", un texto que es a la vez un libro de Historia, un tratado de cosmografía antigua, un libro de aventuras reales y un ensayo sobre el devenir histórico y los descubrimientos, todo ello con una redacción amena y divulgativa, que hace que la lectura sea fácil y placentera.

La obra está profusamente ilustrada con 105 ilustraciones, la mayoría consistentes en mapas de la época, lo que supone un atractivo adicional de esta enciclopédica obra.

Por todo ello sostenemos que se trata de uno de los títulos más recomendables sobre esta expedición sin igual, con permiso del extraordinario "Magallanes: el hombre y su gesta" de Stefan Zweig, una excelente biografía que ahonda en la psicología de sus personajes. En cambio, si la obra de Zweig entra dentro de la literatura histórica y aprovecha al máximo las licencias que permite, este texto cae por completo en el campo de la historia, por su rigor y por estar basado de principio a fin en fuentes históricas y testimonios, sin dejar apenas resquicio a la valoración y opinión personales.

El autor, Mario Ruiz Morales (Moraleza de Zafayona, Granada, 1946), ingeniero en Geodesia y Cartografía, licenciado y Doctor en Ciencias Exactas, fue Premio Nacional Fin de Carrera y es miembro de la Real Sociedad Geográfica y de la Orden Civil de Alfonso X el Sabio. Especializado en Geodesia y en historia de la Cartografía, ha sido Profesor de la Universidad de Granada, en la que ha impartido Geometría diferencial en la Facultad de Ciencias, así como Astronomía, Geodesia y Topografía en la Escuela de Ingenieros de Caminos, Canales y Puertos. Ha sido Director del Servicio de Andalucía Occidental durante mucho años y es autor de numerosos artículos y libros sobre las materias de su especialidad. 
El texto está disponible como libro digital gratuito, en formato PDF, en la página web de libros digitales del Instituto Geográfico Nacional de España: https://bit.ly/2XfKAfY.

\section{Bibliografía}

Pigaffeta. A. (2019). La primera vuelta al mundo, Alianza editorial, Madrid.

Zweig, S. (2019). Magallanes: el hombre y su gesta, Capitán Swing, Madrid. 